\title{
Analysis of IT Applications in Sport
}

\section{Caifeng $\mathrm{Hu}$}

Chongqing wanzhou baian dam ,china ferry road, No.666,Chongqing three Gorges university sports and health college

297416312@qq.com

\begin{abstract}
This paper mainly through the literature material and fieldwork analysis of information technology in sport effects arising. we mainly from three aspects analyze the beneficial effects of information technology. That is school sports, competitive sports and leisure sports. In school physical education major in order to stimulate student interest, develops the student vision; Improve students discover problems, analysis problems and problemsolving skills; Enable quicker for teaching and training and high efficiency; Can expanding capacity in classroom teaching. In competitive projects can good master the sports training process and the athlete physical ability, we through the comprehensive information of foreign sports contrasts. To complement each other to achieve good results; Make the standard of world race unification, reduce of the human intervention. In terms of leisure sports, we mainly promote cultural communication.
\end{abstract}

Keywords- information technology; school sports; sports;leisure sports

\section{INTRODUCTION}

The use of information technology in the "twelfth fiveyear" period to realize scientific development and harmonious development of Chinese society, construction of sports power, promote sports take to the important role to realize the new development, the new span. Sports in this era of economic globalization in economic exchanges, mutual political trust, culture communication, the importance of people-to-people and cultural exchanges, in particular after the 08 Beijing Olympic Games sports for our country won the affirmation of the others in reputation in the international status, the symbol of sports rules and fair and at the same time. Sport is an international trust communication technology of the window, at the same time sports and under the influence of information technology and promote made a leap in the development. Known information technology mainly is mainly used for management and processing information used by the various the floorboard of the technology. It mainly is the application of computer science and communications technology to design, development, installation and implementation of information systems and application software. According to the nature of his participation in sports is roughly divided into three broad categories,School sports, competitive sports and leisure sports, this can include three categories involved in various industry social members of the movement. This article mainly from the analysis of the advantages of information technology in the three kinds of sports.

\author{
Dan Li \\ Chongqing wanzhou baian dam ,china ferry road, \\ No.666,Chongqing three Gorges university sports and \\ health college \\ 51153082@qq.com,
}

\section{INFORMATION TECHNOLOGY'S INFLUENCE ON SCHOOL PHYSICAL EDUCATION.}

The teaching quality of PE teaching is good or bad, is directly related to the prosperity of the motherland and the future of Johnson, a national talent fighting force, the school physical education, let the children develop a good habit of exercise, with lifelong sports consciousness and understand the science reasonable exercise method, information technology has very good effect on school sports.

\section{A. The application of information technology can motivate students' interest in learning, develop students' horizons.}

Interest is the best teacher, students develop the interest is mainly rely on things outside stimulation, caused by his novelty and uniqueness. School of traditional teaching method is a technique to the teacher, then do the demonstration, then later is students, teachers do to correct an action. The introduction of modern information technology can overcome some disadvantage of traditional teaching method, the classroom is more be lively and vivid, novel form diversity. To maintain the attention of students, stimulate the enthusiasm of the students enthusiasm in learning to mobilize the learning. For example, teachers in the teaching of a dive roll forward movement, not to give students do in slow motion, only one or two times the normal action, it is difficult for students to establish a complete image, if the introduction of modern information technology teaching, vivid image, vivid and flexible action can improve the teaching quality, shorten the teaching process. To give students training in music stimulates the boring time, and can be very good to improve student interest in learning. The students did not set up through the video image before, or has made brilliant achievements in a project of the legendary hero, can play to fight for the worship of the determination, to improve the students' learning enthusiasm and love sports, love sports course objective, form lifelong sports consciousness.

\section{B. Information technology can problem, the ability to} analyze and solve problems found good students.

Using modern information technology in teaching of professor action decomposition teaching, analyzed the teaching action, use of multimedia technology to improve the students to discover problems, analyze problems and problem-solving skills. Such as in a set of action show that the right actions and wrong action, and then to group discussion, class to interpret the constituent elements of 
action, difficult point, and respectively discuss the action techniques show the inside of the difference between right actions and wrong action. And as said in the "jump back style high jump teaching", students are difficult to grasp the "jump" feeling. Step in jump at the same time, easy to row errors conveniently hard, but not the same and at the time of the demonstration teachers also can, a slow movement, can lead to mistakes mistakes. So in the teaching using multimedia technology complex movements are simple, will be able to move the static and abstract embody, to increase the students' perceptual knowledge, and get very good effect in the generalization stage.By this way a set of complete demonstration, students in my head there is a complete action representation, can grasp action difficult point, and you can find the emerging issues and guide students. And find other people's problems can improve yourself in the process of rendering errors in the process of practice actions and correct them.

\section{The application of information technology can make the teaching and training more convenient, accurate and efficient.}

In our traditional teaching method in the teaching are the teacher own teaching material and teaching content, make sometimes boring range in, only the interpretation of a single technology, no external stimulation, students easily tired and lose interest. After the use of information technology teaching, the teaching methods and high quality video above achieve the maximization of resource sharing, we won't because of teacher's individual differences or is the school's remote geographical position to affect the quality of the teaching content, so it can well realize the education fair. Especially in the knowledge of a certain language features as well as some advanced teaching it is good for improving the students' interest, and to improve the efficiency of students and teachers are. Teaching and training in the application of high efficiency mainly embodies in the teacher to students to keep a record of wrong action and application of media technology, and national quality action play,To learn to find differences between two actions. Create basic knowledge reuse the correct action representation, in slowly to teach. If conditions allow, to the corresponding music and rhythm, can students know rhythmic movement of heavy difficulty, variation in the corresponding period stimulation can promote action to complete.

\section{Information technology can enlarge the capacity of classroom teaching.}

The use of information technology to expand the capacity of teaching is mainly reflected in the can quickly help students build action representation, in order to achieve effective ability to improve sports skills. According to the formation rules of athletic skills, three stages of generalization, differentiation and automatic action, as well as required in the three stage. In the current school teaching situation, is a network teaching environment, micro-blog is our modern people to use the most popular way, it's convenient, authentic, and high performance provides us an effective way to communicate. Often we will put some teaching experience, due to the limitation of time and space is not formulated and issued to the micro-blog space and so on, so that the students will visit later published experience, such a platform can be taken to the extension of the classroom teaching, the classroom teaching capacity will increase. In short, the network classroom can provide interactive learning environment for students, can optimize the classroom teaching structure, increase the breadth and the capacity of teaching information. At the same time as a supplementary tool for teaching, the teacher's way of thinking and teaching habits changed, to research the growth of teachers in information age; for students, can greatly enhance their self-awareness, conducive to learning accumulation; on learning mode, network advocate lifelong learning, all-round development for students.

\section{THE INFLUENCE OF INFORMATION TECHNOLOGY ON THE COMPETITIVE SPORTS}

The development of competitive sports is good or bad in our developing socialist country and the national system of sports system is a display of China's comprehensive national strength, is also the political, economic and cultural exchanges and international hit the door brick.

\section{A. Information technology allows coaches to master sports training process and the athletes physical capacity in training.}

Today's international sports to achieve great development, the application of information technology is also greatly improved effect on it. Mainly displays in: the installation of computers in all training equipment can accurately measure the athletes in training, the training condition. For example, determination of heart and lung function test athletes on the treadmill when, we are the amount of carbon dioxide to collect test through a mask that is discharged during the movement to determine the maximum level of the body, and exercise capacity. Then the coach through the electronic computer intelligent analysis and processing, which can better grasp of the athletes' advantages and disadvantages; then take remedial measures to practice. So as to avoid the bite before only based on the eyes and experience of athletes training and arrange the training time and intensity, science. Electronic computer in some cases also acted as a sparring partner role. For example, people developed can the chess and the international chess computer, the computer can do the processing speed of the game faster than the average person, and is full of rich experience. To improve the simulation training for people to better

Level will undoubtedly play a huge role in promoting. The computer can also help coaches to better understand the health of athletes. For example, the scientific analysis of physical quality in the selection of athletes, to determine the appropriate sports project, to achieve the purpose of scientific and reasonable, avoid blindness. The previous training due to excessive training to athlete's physical damage, but not for scientific guidance, always cannot find a reason, load can't find a reasonable method for a system to arrange the training schedule and training. With the help of a computer, can according to the actual situation of athletes arrange corresponding amount and types of projects, so that they can seek to improve achievement of sports science. 


\section{B. On comparing the comprehensive information on} foreign sports, to get good grades effect.

Analysis and careful study through the development of information technology on foreign, in a games planning before, our sports meeting members of the preparatory group will carry out analysis on sports reign development situation, to find them in the training of some good training method as well as the achievements. Combined with the training of our country to analyze, find the breakthrough place, to breakthrough to the outstanding achievements of purpose. In order to win.

C. Through information technology to the unification of the world competition standard, reduces human intervention.

A requirement of the competitive sports, regardless of race and gender and age differences, influence of politics, economy, culture, in front of the rules are all equal, is to use time or high degree proof strength place. Through information technology to a platform, will score a project as well as for the selection criteria. Let the sports is not subject to unfair treatment because of their race or gender differences. In football, we can through the information technology equipment $\mathrm{HD}$ to assess some people can't see, fairness or some interest trend and lost, can rarely reduced by can control. Also can be very good to maintain the fairness and the principle of sports.

\section{EFFECTS OF INFORMATION TECHNOLOGY IN LEISURE SPORTS}

Information technology and leisure sports, is with the development of era, the leisure sports is the embodiment of the specific culture in a society, information technology can be a platform for cultural spread out, to promote and encourage local leisure sports. In the international community is the same effect, we have the excellent culture of the Chinese nation through the network, information technology, and sports in the process of communication can inherit and develop.

\section{CONCLUSION}

Information technology is the product of social economy and strength development, sports development and grow more needs the support of information technology.

\section{REFERENCE.}

[1] Jia Shuhong Li Haiming Shen Yuling. Application of [J]. China Education Information Technology in the teaching of physical education.

[2] Zhang Wenqi. How to use modern information technology for teaching $[\mathrm{J}]$ in the sports teaching. Teaching with multimedia, $2013(1)$

[3] Dong Chao on the application of information technology in the university sports teaching[J]. Teaching and research 2013 (3) 